\title{
Personalised Travel Services: an Exploratory Study in Singapore Context
}

\author{
Abhishek Singh Bhati, Cheong Tack Hoong, Jaclyn Chang Lian Fong, Kanwaljit Kaur
}

\begin{abstract}
The aims of the study were to explore the demand for personalised travel services within the affluent customer segment of the outbound travelers in Singapore. The study uncovers the desired service attributes of same consumer segment. The paper begins with a general and broad overview of the travel and tourism industry worldwide and in the Asia Pacific region specifically in Singapore. The international tourism and hospitality sector has grown rapidly over the last ten years and according to the United Nations World Tourism Organisation (UNWTO), international tourist arrivals in 2012 grew to 980 million. Similarly, there has been an increase in outbound travels in Singapore. This growth has been fuelled by the economic growth that Singapore has experienced over the years. The study surveys the current literature to provide data to show the growth of outbound travel from Singapore and the increasing number of affluent Singapore travelers. The study considers an email questionnaire survey to gauge the travel patterns and desires of the affluent traveler market in Singapore. The exploratory findings identify a market for personalized travel services in Singapore and consider an inventory of service attributes desired by the affluent customer segment in Singapore. More specifically, the findings indicate that almost $65 \%$ of respondents preferred personal travel services (PTS) with $70 \%$ who currently book tours through travel agents indicating their preference for PTS. What was particularly interesting was that over $60 \%$ of those who currently engage in self-booking found the idea of PTS appealing. The key draws of PTS are convenience, personalization of itinerary and tour package, experience of consultants and trust. Personalised travel services are targeted to the high income market and the potential demand for PTS among travelers who undertake two or more trips a year was about $\mathbf{7 2 \%}$. Travelers today are looking for more value-added services and interesting tour packages rather than the run of the mill mass tours that many travel agents still provide. Growing affluence and the desire for unique and unusual tours is creating a niche market for travel agencies to exploit. The current and common business model of providing mass tours where
\end{abstract}

Manuscript received September 9, 2013.

Abhishek Singh Bhati is the Associate Dean of Business at James Cook University, Australia (Singapore Campus). 600 Upper Thomson Road, Singapore 574421.65-65766855_(abhishek.bhati@jcu.edu.au)

Cheong Tack Hoong,is a Sessional Lecturer at James Cook University, Australia (Singapore Campus). 600 Upper Thomson Road, Singapore 574421 (tack.cheong@jcu.edu.au)

Jaclyn Chang Lian Fong is a Country Manager, Marketing Department at James Cook University, Australia (Singapore Campus). 600 Upper Thomson Road, Singapore 574421. (jaclyn.chang@jcu.edu.au).

Kanwaljit Kaur is a lecturer at James Cook University, Australia (Singapore Campus). 10, Ang Mo Kio St 54, Singapore 569184 (kanwaljit.kaur@jcu.edu.au). customers are herded on a standard itinerary does not sit well with the well-heeled and sophisticated traveler of today. Today's affluent travelers want to be treated not as mere customers but rather as valuable clients, partnering with the tour agency to create unparalleled and enriching tour experiences.

Index Terms - Personalised service, desired service attributes, consumer trends

\section{INTRODUCTION}

Since the beginning of time, humans have travelled. Initially traders used to travel for business, but around the nineteenth century aristocrats and well to do people started travelling for leisure [1]. The World Tourism Organization (UNWTO) describes tourists as people who travel out of their current environment for leisure or other purposes. Tourism is about experiences, whether exploring an unfamiliar culture, shopping, lying on a beach or enjoying sports events away from the local environment [2].

Tourism has emerged as one of the most remarkable phenomena of the past century. Every year, more and more people take part in tourism activity and for many countries in the world; tourism is a dynamic and fast growing sector of the economy. Based on research done by the Future Foundation, consumers perceive holidays as the number-one luxury product. The desire for holidays has been driven by consumer prosperity from rising incomes [3].

Growth is being driven by emerging markets such as Asia and South America [4]. In the past 50 years, tourism growth has been phenomenal. Aided by technology and affordability of air travel, tourism has grown at an annual rate of 7\% [5]. The study found that between 1959 and 1999, the number of international arrivals rose from 25 million to about 664 million. The World Trade Organisation (WTO) reported that international tourism accounts for about $12 \%$ of international spending and creates 1 in 12 jobs worldwide. Tourist activity in the Asia Pacific region echoes this tremendous growth. The booming outbound Asian markets are China, South Korea and Malaysia, all of which are increasing at more than $20 \%$. Taiwan, Japan, Singapore and India are also growing at double-digit rates [4]. The report further highlights that despite the economic uncertainty, $32 \%$ of respondents in the study said they would travel more in 2012 than in $2011,37 \%$ plan similar levels and only $19 \%$ want to reduce their travel.

The tourism industry is described as a set of related activities and processes a tourist will interact with during his 
travels. In words of Macintosh and Goeldner [6] tourism is "the sum of the phenomena and relationships arising from the interaction of tourists, business suppliers, host governments and host communities in the process of attracting and hosting these tourists and other visitors". The tourism industry is geared towards the nature of travel which is either outbound, tourists travelling out of the usual environment or inbound, tourists travelling in a host environment. Outbound tourism is the tourism of resident visitors outside the economic territory of the country of reference [7].

Presently, the tourism and travel industry is very much based on the 'old' model of arranging pre-prepared itineraries and standard tours that do not give sufficient importance or significance to the different needs of the travellers. The Singapore leisure industry has largely remained the same over the last 50 years in terms of a group products business model. But the consumer market has begun to get more mature and sophisticated in holiday demands. One of the researchers, who has been actively managing a travel agency for the past 30 years, found that more and more travellers today began approaching his agency to design and package more 'customised' tour packages for them. This feedback triggered the idea of an exploratory research to study the viability and feasibility of personalising the travel experience for customers. If the findings did indeed suggest the need and demand for such customisation, it would open up a whole new interesting way of managing the travel business.

The basic idea is to provide a one-stop personalized service, which provides flexibility and convenience to the customer. Rather than visiting the retail agency outlet, customers can be served at their preferred venue and time. For the target group, the holiday experience begins with the first meeting, with the creation of distinctive experiences through the travel agency.

This paper attempts to understand the travel behaviour of outbound tourists especially the niche segment of affluent travellers who are in need of customised travel advice. For the purpose of this study, customers with annual household income of $\mathrm{S} \$ 100000$ and more are defined as affluent. The targeted customer segment does not have the time to search for travel services and destinations to satisfy their travel needs. The survey of current literature identifies a need for customised advice. However there is little empirical evidence of presence of sustained demand and preferred service attributes. This study conducts a survey of a sample of the target market and considers the findings in evaluating the demand for personalised travel services (PTS) in Singapore and preferred service attributes of outbound customers in Singapore. The findings are particularly relevant to travel service providers in reaching out to this customer segment.

\section{A. $\quad$ Trends in the Global Travel Industry}

The global demand for travel and tourism provides unprecedented opportunities. Global outbound traffic spending has been rising rapidly. In total, outbound travel spending grew $8 \%$ to $€ 828$ billion in 2011 [4]. In addition, spending per trip has also increased. Asians spend the most per trip, ahead of Americans and Europeans. In tandem with the global trends, Asia Pacific has also seen a $14 \%$ increase in outbound travel [4]. One of the key driving forces for this increase is the rise of large, relatively well-off middle classes in the region. A recent study by UNWTO [2] on international tourist movements and trends shows positive growth worldwide from 1995 to 2020 . The study forecasts that the outbound travel sector will grow from 1 billion in 2010 to 1.56 billion in 2020. It also recognises a shift in focus from Europe to East Asia Pacific (EAP) wherein the EAP region will contribute to $25.4 \%$ arrivals in 2020 , up from $14.4 \%$ in 1995 .

Moreover, travellers are shifting from buying consumer products to buying experiences, especially consumers in Hong Kong, Japan, Republic of Korea, Singapore and Taiwan [8]. As a result, demand for customised tours, quality assurance and interactive experience is on the rise. The same report (which involved a content analysis of 766 travel reports) identified the following key trends in the Asia-Pacific region:

- Travel has become more activity-based rather than destination-based

- Travel experiences and customised tours have become more important

- Tastes and travel spending have become more polarised

Delivery of unique travel experiences that engage consumers will be essential. This view is supported by the fact that an experience economy is emerging in which there is greater involvement of both service providers and customers in the service delivery process [9]. Customers want to play a more active role in the design of their travel plans by declaring their preferences for customised packages and itineraries. Further evidence of this trend is provided by Smith [10], who has concluded that a tourism product is made up of five elements: physical plant, service, hospitality, freedom of choice and involvement.

As consumer living standards rise, a strong sense of autonomy and increasingly abundant travel experiences are causing the travel market to become more segmented. Travellers will always have different purposes and preferences in their selection of tours. These differences are accounted for by consumer age, lifestyle, educational and income backgrounds [11]. Packaged tours provide less flexibility due to the large number of designated sites to be visited [12].

Many travelers today participate in 'special-interest' tours, such as culinary tours, adventure tours, nature-based travel, cultural and heritage tours, agri-tourism and such [13]. The growth of these special-interest tours has been further documented in the Brown \& Hudson [14] ongoing survey of future trends in the luxury travel market. The most appropriate and relevant way to cater to such travelers is through an interactive personalized and customized "high touch" approach [15] [16]. 
A study by marketing interactive website in 2011 reveals that even during an economic slowdown, one group of consumers - the affluent travellers - did not alter their travel frequency or patterns. Though the customer segment was resilient through economic crises, it demanded personalised attention by travel agent and customised advice on their travel needs [17].

Research by Visit Britain [18], Britain's national tourism agency, has elucidated some of the characteristics of this economically important luxury travel market. Based on this research, it categorized luxury travelers into three key groups - the Gold (overt, demonstrates and broadcasts wealth), the Platinum (less overt, comfortable luxury) and Black (understated, minimal, ultimate in exclusivity). The final category represents an emerging and growing group of travellers interested in luxury - seamless and hassle-free travel experience. The agency pointed to a growing need for travel suppliers to build customized packages that are highly tailored to the individual's tastes and specifications. Similarly, exploratory interviews carried out with travel industry leaders and retail travel consultants support the above findings [19]. According to the study, customers are becoming more sophisticated and knowledgeable and are looking for specialised holidays experiences different from the needs of mass tourism. Modern tourists demand a range of services from service-providers and select the most preferred option. Today, tourist experiences are heterogeneous rather than homogeneous [20]. In other words, service providers should move towards offering a range of travel packages, preferably customised to travellers' needs.

The purchase of an expensive, complex service such as an international holiday requires a great deal of information and reliable expert advice. The risks involved in such a purchase are substantial. Hence, personal, specialised and professional travel services are needed by travellers, especially high net worth individuals [21]. Travellers have resorted to the Internet for travel related information but the vastness of the information available online exerts time demands [22] for consumers to access and assess information and assemble it into a personalised package.

According to Peter J. Bates, Founder and President of marketing communications consultancy Strategic Vision, customisation is one of the central components of success in marketing to luxury travellers. The ability to provide personalised services is valued among the luxury travellers [14]. Further, an article entitled 'Selling Luxury: When 5 stars isn't enough' strongly suggests that luxury travellers today want optimised vacation experiences tailored exclusively by an expert who understands their personal needs [23].

The target market for personalised travel services is the more affluent segment of travellers. The growth of this market segment is reinforced by the findings of an Asia Pacific PAX survey done in 2011 by Synovate, a global marketing research company. The survey involving 1,678 affluent Singaporeans revealed that this group feels the need for exclusivity and understands quality perception. Further, there is a large increase in the purchase of big-ticket items, such as travelling. Travellers from Singapore ranked the highest in taking leisure trips. Three out of four affluent Singaporeans $(73 \%)$ went on one or more leisure trips, an increase of $14 \%$ from 2010 . This finding points to a significant affluent target market. Customers are demanding higher service levels, better quality information and personalised packages. $38 \%$ of travellers will pay up to $20 \%$ more for customised products and services [5].

In 2011, 218,199 individuals in Singapore had annual incomes of $S \$ 100,000$ and above [24]. This represents about $21 \%$ of all resident taxpayers. Household income from work in 2010 increased in tandem with strong economic growth. The median and average household income in Singapore increased from $\mathrm{S} \$ 3600$ in 2000 to $\$ \$ 5000$ in 2010 [25]. With the exception of a couple of years, household income has been rising steadily. This translates to higher disposable income for spending on discretionary items such as travel and tourism.

Singapore is a small country with limited natural scenery and leisure places for its people to enjoy. Hence, many Singaporeans and permanent residents prefer to travel out of Singapore and travel is a luxury that many are willing to pay for. Early in this report, data from the ITB World Travel Report 2011/2012 and the Singapore Department of Statistics has shown there is tremendous growth in tourist activity in recent years. Over the years, Singapore travelers have become very sophisticated and constantly demand higher quality travel services and experiences. As noted by Brown \& Hudson [14], the ever-growing demand for personalized customer service requires a strengthened relationship between travel agents and clients. The suggestion that travel agents provide better service than is available on the Internet has been put forward by a number of authors such as Caragata \& Demont [26], Pappas [27] and Furger [28]. In addition, the results and findings of the survey confirm the demand and need for personalized travel services. Travel agencies need to develop more niche products and to cater to tourists who are indulging their greater freedom to travel [5].

Global marketing research company Synovate has proven that three out of four affluent Singaporeans went on one or more leisure trip per year [29]. The survey finding that more than $61.9 \%$ of respondents make 2 or more leisure trips within a 12-month period proves that there is sustainable growth in this business. Strongly supporting the recommendation of providing personalised travel services is the survey finding that many affluent travellers are rather dissatisfied with the present service they receive from travel agents/travel arrangers.

An article 'The World of Travel in 2020' reported that the 'one size fits all' approach will no longer work. Travellers of the future will require travel agents to constantly update their product offerings. The article goes on to suggest that over the next 15 years, travel agencies that can offer seamless services will appeal to the time-starved traveler [30]. 
Thus, travel agents should move from a focus on transaction processing to the provision of consultant services (expand advisory functions and concentrate on the provision of information and details that are not available on the Internet) and there is an opportunity for travel agents to focus on specific markets and specialised activities.

\section{B. Singapore Travel Industry}

Outbound tourist activity in Singapore has moved in parallel with increased outbound travel in the whole Asia Pacific region. The number of outbound departures of Singapore residents has shown a strong and steady increase from 5.5 million travellers in 2006 to 7.3 million travellers in 2010 [31]. The small physical size of Singapore, the busy work schedules, limited local leisure spots and activities, accessibility and its modern and convenient transport services are factors that have resulted in greater outbound traffic. Travel is a lifestyle for Singaporeans, with more than $50 \%$ of the population making at least one overseas trip in a year [25].

Not only has tourism and leisure travel increased rapidly, there is a trend towards more personalised travel services as well, especially in the luxury market. Brown \& Hudson [14] are undertaking a qualitative and quantitative research project, 'The Future of Luxury Travel, A Global Trends Report' to be carried out from $2011-2013$ to measure the main trends and challenges of the luxury travel industry. The study findings reveal that the need for personalisation will continue to grow within the luxury travel industry and points to an increased demand for concierge-type travel services.

The Singapore leisure agency industry has largely remained the same over the past 50 years in terms of its group products business model. In the past, most travel agencies adopted product-oriented strategies to cater to the mass market traveller and many tourism products were limited to fixed forms. However, the consumer holiday market is increasingly mature and sophisticated. As travellers look for personalisation, agencies must develop strategies to cater to these needs and desires. The emerging market presents a contrast with the mass market segment involving large group size, bargain price deals and fixed pre-packaged tours. It represents a trend towards service delivery that is highly focused on service innovation for its customer segments with customized itinerary [32].

\section{RESEARCH OBJECTIVES}

As stated in the introduction this paper has two objectives. The first objective is to establish the market potential for personalised travel services (PTS) in Singapore. The second objective of the paper is to create an inventory of desirable service attributes of PTS. PTS is a one-stop personalized service, which provides flexibility and convenience to the customer. Rather than visiting the retail agency outlet, customers can be served at their preferred venue and time. For the target group, the holiday experience begins with the first meeting, with the creation of distinctive experiences through a travel concierge. The key research objectives were summarized as follows:

- To identify the demand for personalized travel services among affluent Singaporeans and Singapore Permanent Residents on outbound leisure travel.

Currently, the industry is focused on meeting the needs of the mass travel market, which is saturated and highly competitive. With the increasing affluence of holiday makers and the frequency of travel, the market is becoming more segmented, leading to demand for differentiated products and services. The study was designed to focus on Singaporeans and permanent residents as they form the core and sustainable customer base of the holiday travel market.

- To establish the preferred service attributes of travelers within the PTS target market

To generate a better understanding of the needs of this market segment, it was important to verify and substantiate them.

\section{METHODOLOGY}

The primary data collection instrument used was a survey questionnaire. Essentially, the sampling method was a combination of judgment and convenience approaches [33]. Since the proposed service was targeted at the high income segment of travellers, households with an income of at least $\mathrm{S} \$ 100,000$ per annum were judged to be an appropriate survey sample. Judgment sampling was used as the researchers were well able to gauge the type of units that would be fit and appropriate to survey, primarily affluent households. Convenience sampling was applied in that the subjects were selected because of their convenient accessibility and proximity to the researchers. This sampling framework was deemed to be relevant for this exploratory study to give a basic and general insight into the travel habits and needs of this affluent group of travellers.

Respondents were selected from business associates and customers of travel related products. Factors such as ease of contact, availability (e-mail addresses) and known willingness to participate in the survey were considered. This approach provided a gross estimate of the results, without incurring too much cost and time to gather the data. The survey consisted of 11 questions, in a combination of open and close-ended format. A total of 100 e-mail invitations were sent out and 42 completed surveys were received, giving a response rate of 42 . The questions were designed with the research objectives in mind and focused on finding out:

- demand for personalised travel services

- the criteria participants use in picking a travel agent 
- the service attributes they would expect from personalised travel services

- the frequency of holiday travel who arranged their trips

- their experience with their travel arranger

- their acceptance of 'standard tour packages' offered by travel agents

Additionally, some respondents were hesitant to participate despite being assured of confidentiality and anonymity and this affected the response rate. Nevertheless, sufficient responses were received to draw meaningful conclusions pertinent to the research objectives.

\section{FINDINGS}

The survey was conducted to validate the two objectivesto establish if there is a demand for personalised travel services (PTS) and to ascertain the desired attributes of such personalised travel services. The survey results were therefore analysed bearing in mind these two objectives.

The key findings with respect to the demand for personalised travel services are summarised as follows:

- $\quad 64.3 \%$ of all respondents indicated a preference for PTS

- $\quad 62.5 \%$ of those who currently engaged in self-booking said yes to PTS

- $70.0 \%$ among those who currently booked through travel agent/arranger said yes to PTS

- $\quad$ The five most frequently cited desired attributes of PTS were convenience, personalized itinerary, personalized package, experienced consultants and trust factor

\section{A. Preference for PTS}

The $64.3 \%$ endorsement by all respondents for PTS is a clear indication of the demand for a more personalized and professional service beyond what is currently available in the market. Of particular significance is the finding that $62.5 \%$ of those respondents who currently engage in self-booking were favourable towards the idea of PTS. This willingness to shift from self-booking to PTS suggests that these respondents, given the appropriate choice, would prefer the service of a professional high-touch agent.

Among the respondents who were actually satisfied with their current travel agent, a large number $(70 \%)$ were still interested in utilising PTS. While comfortable with the traditional service of a travel agent, this group would consider PTS, given a choice. As many as $61.9 \%$ of all respondents indicated that they were not happy to book standard packaged holidays provided by travel agents.

\section{B. Demand Factor in Terms of Frequency of Travel}

The respondents were from an affluent group with a household income of at least $\mathrm{S} \$ 100,000$ per annum. Within any 12 -month period, $100 \%$ of respondents took at least one holiday trip a year. $42.9 \%$ take two trips a year, $7.1 \%$ take 3 holidays a year and $11.9 \%$ take more than 3 holidays a year. The demand for PTS among those who take two or more holiday trips is as high as $71.4 \%$ as against those who make only one trip $(57 \%)$.

\section{Desired Attributes}

Table 1 provides in descending order the desired attributes of service the respondents expect from their travel agent. This order is based on the number of respondents who selected each attribute.

TABLE 1

DESIRED SERVICE ATTRIBUTES OF AFFLUENT OUTBOUND TRAVELLERS IN SINGAPORE

\begin{tabular}{lll}
\hline Ranking & Attribute & $\begin{array}{l}\text { Number } \\
\text { respondents }\end{array}$ \\
\hline 1 & Personalised Itinerary & 29 \\
2 & Convenience & 25 \\
2 & Personalised package & 25 \\
4 & Experienced travel & \\
4 & consultant & 24 \\
6 & Trust & 24 \\
6 & Confidence & 20 \\
8 & Personal tour guide & 20 \\
9 & Privacy & 16 \\
\hline
\end{tabular}

The top five main attributes are congruent with the value proposition of PTS, which is to provide convenience, customisation and professional service staff. The service attributes are covered in detail in the discussion section.

\section{DISCUSSION}

The literature review and the survey results are clear proof that there is a real potential to target affluent travelers, who represent a lucrative niche market for personalized travel services. As seen in the response to question nine in the survey, there is genuine market potential for personalised travel services. Strategies by organisations to reach the affluent customer, such as, the launch of a 'luxury travel' credit card by the Hong Kong \& Shanghai Banking Corporation (HSBC) in Singapore confirms the above findings. The credit card features 'travel and lifestyle butler' travel experiences for its cardholders and is targeted at consumers belonging to the high net worth and mass affluent segment who desire personalised travel services [34]. This is clear evidence that there is indeed a ready market of affluent travelers who want personalized and customized travel services. Furthermore, the response to question one in the survey exhibit that travelers who take two or more holiday trips a year have a greater preference for personalized travel services. This result could be attributed to the fact that 
frequent travellers are likely to fall into the affluent traveller category and hence are more demanding.

Several studies emphasize the importance of addressing the needs and wants of the customer instead of packaging the service offering with general features [15] [35]. The five most important service dimensions for people when they are planning and arranging their travels abroad are reliability, handling complexity, assurance, good deals and security [36]. The top attributes most frequently cited are a good reflection of the desired dimensions when the select group of respondents are thinking about their next holiday. Questions such as Where to go, what to see and things to do as suggested by personalized itinerary came in as the number one attribute. Furthermore, these affluent travellers tend to be time-starved, so having an experienced travel consultant tailor a holiday package for them does seem a logical service development to cater to their needs.

The survey finding confirms that the desired attributes are in congruence with the five value proposition of PTS identified by Cheyne et al [36]. For example, professionalism means staff members are reliable and provide assurance that they are capable of meeting all aspects of the travel needs of their customers. Handling complexity and ensuring security is related to providing an excellent customer experience and good deals are related to value. The Trust attribute, although ranked fifth in order of frequency cited, is just as important because of the time and financial commitment customer invest in the holiday for their family. In summary, the respondents were concerned about their front-to-end experience in holiday planning highlighting the need for seamless travel experience [11] [37]. The report 'Mega-Trends of Tourism in AsiaPacific' has postulated that travel agents need to transform themselves into travel consultants and advisors and this is best done by ensuring personalized services and arming themselves with thorough knowledge and expertise to provide the seamless travel experience to customers. Furthermore, the changing preference of travelers for more customized travel packages requires that the travel consultant develop skills in integrating different sub-products into a personalized package to suit customers' preferences.

\section{CONCLUSION}

Studies and data on tourist activity highlight emerging trends in the tourism and hospitality sector, particularly regarding the growing affluence of travelers and their changing preferences. The survey discussed in this paper further justifies the need to expand into the provision of such personalized and customized travel services.

The feedback from respondents indicates that the travel market has matured and is evolving into niche markets. Further, the suggestions from respondents confirm that the gap in the market place can be covered by the introduction of personalised travel services (PTS). The outbound travel market is getting more affluent and sophisticated and is seeking improvements in the products and services provided by travel agencies. This evolution will lead to an increasing demand for more high-touch travel services.

Greater sophistication and more knowledgeable travelers globally and specifically in Singapore are changing the landscape of the travel and hospitality industry. A departure from standardized mass market type of travel packages to more specific and special travel itineraries and activities is increasingly likely. This will call not only for a more personalized approach, but also an 'on-call' travel service that can quickly and expeditiously meet the needs of this niche market.

Although the travel industry is highly competitive, most travel agencies have limitations in catering to affluent travelers. This is due to the business model they use, which involves a retail set up, fixed operating hours and poorly trained staff.

\section{FUTURE RESEARCH}

The literature reviews and survey discussed in this paper were carried out as exploratory research to verify the demand for personalised travel services and to identify the key service attributes desired by customers. As mentioned earlier, this demand has been clearly established through this exploratory research and an inventory of key attributes is compiled. This paves the way for more in-depth research to identify the demographic and psychographic characteristics of the affluent customer segment to identify the target market and to identify more detailed and specific requirements of the Singapore affluent traveller market.

\section{ACKNOWLEDGMENT}

The authors would like to thank all respondents who participated in the survey for their time and effort. 


\section{REFERENCES}

[1] Yeoman, I. (2008). Tomorrow's Tourist. London:Routledge.

[2] UNWTO Tourism Highlights (2011). Retrieved on 2 February 2012 fromhttp://mkt.unwto.org/sites/all/files/docpdf/unwtohighlights11enhr_ 1.pdf

[3] Silverstein, M., Fiske, N. \& Butman, J. (2005). Trading up: why consumers want new luxury goods - and how companies create them. New York: Portfolio.

[4] ITB World Travel Trends Report 2011/2012. Retrieved on 20 January 2012 from

http://www.itbberlin.de/media/itbk/itbk_media/itbk_pdf/WTTR Report komplett we b.pdf

[5] Vasja, M. (2010). New Tourist Products for New Tourists' Expectations.Faculty of Tourism and Hospitality Management in Opatija. Biennial International Congress. Tourism \& Hospitality Industry. 1075-1085.

[6] Macintosh, R. W. \& Goeldner, C. R. (1986). Tourism: Principles, Practices,Philosophies. Wiley (New York)

[7] Organisation for Economic Co-operation and Development. (2001). Glossary of Statistical Terms. Retrieved on 23 January 2012 fromhttp://www.oecd.org/home/0,2987,en_2649_201185_1_1_1_1_1,0 0. html

[8] Mega-Trends of Tourism in Asia-Pacific. (2006). Retrieved on 30 January 2012 from http://www.tourism.wuwien.ac.at/summit/material/megatrend_in_asia-pacific.pdf

[9] Pine, B.J. \& Gilmore, J.H. (1999). The Experience Economy: Work is theatre and every business a stage. Boston MA: Harvard Business School Press.

[10] Smith, S.L.J. (1994). The tourism product. Annals of Tourism Research , 21(3), 582-595.

[11] Chang, J.C. (2009). Taiwanese tourists' perceptions of service quality on outbound guided package tours: A qualitative examination of the SERVQUAL dimensions. Journal of Vacation Marketing, 15(2), 165 178. doi: $10.1177 / 1356766708100822$

[12] Pizam, A. \& Mansfield, Y. (1999). Consumer behavior in travel and tourism. New York. The Haworth Hospitality Press.

[13] Figart, F \& Nelson, L. (2005, May). The growing market for special interest tours. Travel Essentials. Courier. Retrieved on 4 February 2012 from

http://torc.linkbc.ca/torc/downs1/TheGrowingMarketforSpecialInterest Tours.pdf

[14] Brown \& Hudson (2011). The Future of Luxury Travel. A Global Trends Report. Retrieved on 31 January2012 from http://www.iltm.net/files/the_future_of_luxury_travel_report.pdf

[15] Sergey, V. A. (2011). Modern trends of travel industry management development: prospects and innovative approaches. European Researcher(5-2), 805-808.

[16] Batet, M., Moreno, A., Sánchez, D., Isern, D., \& Valls, A. (2012). Turist@: agent-based personalised recommendation of tourist activities. Expert Systems with Applications, 39(8), 7319. doi: 10.1016/j.eswa.2012.01.086

[17] Marketing-interactive.com. (2012). In the Lap of Luxury. Retrieved on 3 February 2012 from http://marketing-interactive.com/news/23623

[18] VisitBritain (2010). Luxury Tourism Trends Summary. Retrieved on 3 February 2012 from http://www.visitbritain.org/Images/Luxury\%20\%20Tourism\%20Trends tcm29- 15230.pdf

[19] O' Brien, P. F (1998). Electronic Commerce, the Internet and Travel Cybermediaries.Australasian Journal of Information Systems. 6(1).

[20] Uriely, N. (2005). The tourist experience: Conceptual developments. Annals ofTourism Research, 32 (1).

[21] Warrington,T. (2004) "Trading up: The New American Luxury". Journal of Consumer Marketing, Vol. 21(2): 157 - 158

[22] Tschanz, N. \& Klein, S. (1996) Internet Strategy Development in Tourism - Concept and Case Study, SISNet Research Workshop 'Internet and Business', SISNet, Lisbon.

[23] Saltzman, Dori (2012, January). Selling Luxury: When 5 Stars Isn't Enough. Travel Report 2011. Retrieved on 25 January 2012 from http://www.travelmarketreport.com/leisure?articleID $=6786$

[24] Inland Revenue Authority of Singapore. Annual Report 2010/2011. Retrieved on 4 February 2012 from http://www.singstat.gov.sg/
[25] Department of Statistics. (2005). General Household Survey 2005. Retrieved on 31 January 2012 from http://www.singstat.gov.sg/

[26] Carragata, W. \& Demont, J. (1999). "Travel: A road more travelled: Agencies must adapt as online trip bookings grow". Macleans, 12 July: 42

[27] Pappas, C. (1997). "Have modem, will travel". Home Office Computing 15(7): 46-47

[28] Furger, R. (1997). "Online travel: Time versus money". PC World 15(7): $33-35$

[29] Synovate (2011). Asia Pacific PAX survey. Retrieved on 4 February 2012 fromhttp://www.synovate.com/contact/

[30] Future Foundation (2005). The World of Travel in 2020. Retrieved on 4 February 2012 from http://rss.hsyndicate.com/file/152002289.pdf

[31] Singapore Tourism Board (2011). Annual Reporton Tourism Statistics. Retrieved on 13 January 2012 from http://www.stbtrc.com.sg/images/links/X1Annual_Report_on_Tourism Statistics 2010 2011.pdf

[32] Welch, S.B. (2009). Companies must Innovate, Regardless of Economy. Crain'sDetroit Business, 25 (22).

[33] Groves, R. M. (2004). Survey methodology. Hoboken, NJ: J. Wiley.

[34] McCaughey, R. (2011). HSBC credit card targets jetsetters in Singapore. Retrieved on 4 February 2012 from http://www.vrlfinancial-news.com/default.aspx

[35] Skyscanner reveals 2012 travel trends. (2012). (Journal, Electronic). Retrieved from http://search.proquest.com.elibrary.jcu.edu.au/docview/913312441/fullt ext?accountid $=16285$

[36] Cheyne, J., Downes, M. \& Legg, S. (2005). "Travel agent vs internet: What influences travel consumer choices?" Journal of Vacation Marketing. 12(1):48

[37] Shirshendu, G., \& Sanjit Kumar, R. (2010). Service quality dimensions of hybrid services. Managing Service Quality, 20(5), 404-424. doi: $10.1108 / 09604521011073713$

This article is distributed under the terms of the Creative Commons Attribution License which permits any use, distribution, and reproduction in any medium, provided the original author(s) and the source are credited.

*Abhishek Singh Bhati is responsible for overseeing academic governance, administration and introducing strategies to enhance student experience for the School of Business programs offered in Singapore Campus. He has worked in the education industry with leading providers for more than 12 years. He is particularly interested in impact of tourism on the economy as well as social sustainability. His $\mathrm{PhD}$ (candidate) thesis studies tourist vandalism, motivation factors of a vandal's behaviour and effectiveness of stakeholder responses. His other projects include incorporating 'work integrate learning' (WIL) based learning strategies in tertiary education. His recent project involve implementing WIL in university curriculum.

Cheong Tack Hoong was originally from Malaysia, but has worked and lived in Singapore since 1973. After completing a Bachelors of Science (1972) at the Universiti Sains Malaysia, one of Malaysia's oldest and highly rated institutions, he has embarked on an extensive career in Tourism and Marketing in Asia's leading travel companies. Since 2010, he has served as Director of Corporate Travel Services Pte Ltd, a leading travel management company based in Singapore. Prior to this, he was Group Chief Executive in the same organization. Over the last 40 years, he has held various senior management positions in the regional travel industry, including:

Mr Cheong has also served as a board member of the Singapore Polytechnic School of Business Advisory Council since 1998 and 
has been an invited speaker at key tourism management conferences during the course of his career.

Chang Lian Fong (Jaclyn) received her BBus degree in 2007 from James Cook University and her MBA in 2012 from James Cook University. She joined James Cook Australia (Singapore Campus) and her current appointment is Country Manager in the Student Recruitment and Marketing Department. Her research interests are Organizational Culture, Marketing and Tourism.

Miss Chang is the member of Golden Key International Honour Society. In 2006, she was awarded the "Excellent Service Silver Award" jointly presented by the Singapore Hotel Association and SPRING Singapore. In 2012, she received the "Award for Excellence" for creating effective partnerships and innovative marketing strategies at the University.

Kanwaljit Kaur was born in Singapore in 1959. She received the BSC (Econs) in Management Studies degree from the University of London, UK in 1990 and MBA from James Cook University in 2012.

From 1979 to 1988 , she was an officer in the Republic of Singapore Air Force. Subsequently, she worked in the private sector before commencing her undergraduate studies. After graduation, she entered the education sector and has lectured since 1991. Since 2008, she has been a lecturer in James Cook University, Australia (Singapore Campus). Her research interests include teaching and learning pedagogies, marketing and consumer behaviour.

Ms Kaur is a member of the Golden Key International Honour Society. She received the 'Best Employee of the Year' award in 2010. 